\title{
Evaluation of antifungal properties of some medicinal plants against Aspergillus flavus isolated from contaminated Corn in vitro
}

\author{
Sahar Omidpanah ${ }^{1}$, Abolfazl Haseli ${ }^{2}$ and Azadeh Manayi ${ }^{3, *}$ \\ ${ }^{1}$ Biology Department, Islamic Azad University, Jahrom Branch, Shiraz, Iran \\ ${ }^{2}$ Head of Veterinary Hospital of Abarkoh, Yazd, Iran \\ ${ }^{3}$ Medicinal Plants Research Center, Faculty of Pharmacy, Tehran University of Medical Sciences, Tehran, Iran
}

\begin{abstract}
Aspergillus strains especially A. flavus and A. parasiticus are the most frequent grains molds producing carcinogenic aflatoxins, which is one of the main challenges in the agriculture and food industries. Chemical pesticides for control of the fungi have adverse effects on human health and environment; therefore, the necessity of finding acceptable substitutes for these substances seem apparent. In the present study, aqueous extracts of aerial parts of zataria (Zataria multiflora Boiss.), thyme (Thymus vulgaris L.), pennyroyal (Mentha pulegium L.), peppermint (Mentha piperita L.), senna (Cassia senna L.), and basil (Ocimum basilicum L.) along with flowers of safflower (Carthamus tinctorius L.) were examined against A. flavus isolated from contaminated corn. The extracts with different concentrations (100-600 ppm) and poly ethylene glycol (PEG) with equal osmotic potential of the plant extracts were added to potato dextrose agar (PDA) medium to evaluate fungus growth after 7 days and using agar dilution method. All concentrations of the extracts significantly inhibited the fungus growth in comparison with each other and the control, while the extracts of thyme and zataria were manifested to be the most effective prohibition with minimum inhibitory concentration (MIC) of $600 \mathrm{ppm}$. Potency of the plants' extracts on the growth of fungus was evaluated as follows: zataria> thymus> safflower> peppermint> pennyroyal> senna> basil. Results of this study presented aqueous extracts of thyme and zataria as effective preservatives against growth of A. flavus for corn products.
\end{abstract}

Keywords: Aspergillus flavus; Carthamus tinctorius; Thymus vulgaris; MIC; Zataria multiflora.

\section{Introduction}

Many various kinds of fungi can abundantly be found all around us especially in soil and air, contaminated grains on stored food commodities and agriculture products. Aspergillus strains especially A. flavus and A. parasiticus are the most frequent grains molds producing carcinogenic aflatoxins ${ }^{1,2}$. Aspergillus flavus is a saprophyte fungus with pathogenic property for both plants and animals ${ }^{3}$. Secretion of hydrolytic enzymes by the fungus causes strong affinity to colonize in various foods ${ }^{4}$. Aflatoxins, produced by A. Flavus, are structurally related to difuranocoumarin derivatives, among them aflatoxins $B_{1}$ is highly toxic, mutagenic and carcinogenic ${ }^{5,6}$. These toxins usually contaminate agricultural products including corn,

*Corresponding author: Azadeh Manayi

E-mail address: Manayi@ sina.tums.ac.ir

DOI: http://dx.doi.org/10.13171/mjc.3.6.2015.01.09.13.22.manayi 
peanuts, wheat, cotton and tree nuts causing economic loss all around the world ${ }^{3,7}$. Because of high toxicity of aflatoxin, prevention of the fungus growth on the agricultural and food products has become a great concern of the scientists. In the previous studies, inhibition activity of essential oils and extracts of some plants were examined toward A. flavus or other species of the fungi ${ }^{8-12}$. Zataria (Z. multiflora) grows widely in Iran, Afghanistan and Pakistan with traditional uses as an antiseptic, carminative, stimulant, diaphoretic, diuretic, anesthetic, anti-spasmodic and analgesic ${ }^{13}$. Thyme (T. vulgaris) is flowering plant used as expectorant, antitussive, antibroncholitic, antispasmodic, anthelmintic, carminative and diuretic properties in the folk medicine. Pennyroyal (M. pulegium), peppermint (M. piperita) and basil (O. basilicum) are widely cultivated in the most part of the world for their medicinal, ornamental properties as well as flavour and aroma for food ${ }^{14,15}$. Leaves and fruits of senna (C. senna) are well known laxative regarding to their anthraquinons ${ }^{16}$. Safflower (C. tinctorius) has reputation for curing several diseases and also for its oil reach seeds ${ }^{17}$. Eessential oils of some plants against A. flavus were tested and the results showed that oils of Cinnamomum zeylanicum, $M$. piperita, O. basilicum, Origanum vulgare, Teloxys ambrosioides, Syzygium aromaticum, and T. vulgaris totally inhibit the fungus growth ${ }^{18}$. The oil of $T$. vulgaris efficiently arrested aflatoxin $\mathrm{B}_{1}$ production by $A$. flavus better than most of the synthetic fungicides ${ }^{19}$. According to the results of a study, strong antifungal activity of thyme oil could be attributed to thymol or synergism of other major components of the essential oil ${ }^{20}$. Antimicrobial effects of essential oils of Z. multiflora toward yeast, Gram-positive and Gram-negative bacteria as well as A. flavus and A. parasiticus have been well documented ${ }^{21-23}$. Protective effect of carvacrol, the main phenolic compound of Z. multiflora oil, has been evaluated against some fungi; therefore, it seems that the compound is responsible for inhibitory effect of the plant oil ${ }^{24,25}$. While, both polar and non-polar extracts of $C$. senna did not exhibit antifungal activity toward A. niger ${ }^{26}$. Inhibitory effect of oil of M. piperita was examined toward A. fumigatus, A. flavus and A. ochraceus during 10 days. The results indicated that the oil of $M$. piperita inhibits growth of all tested fungus species ${ }^{27}$. Menthol, the main organic component of $M$. piperita oil, effectively contributed to high antifungal activity of the oil ${ }^{28}$. In addition, oil of M. pulegium, which was reach in puelgone, had great potential for antibacterial and antifungal activities against tested microorganisms including A. niger and A. flavus ${ }^{29}$. Oil of M. pulegium from Iran, belongs to piperitone/piperitenone type, showed inhibition against $A$. niger ${ }^{30}$. Since chemical pesticides have adverse effects on human health and environment, the necessity of finding acceptable substitutes for these substances seems apparent. In the present study, aqueous extracts of some medicinal and edible plants including zataria, thyme, pennyroyal, peppermint, and basil belong to Lamiaceae and senna, a species of Fabaceae family, with safflower, a flowering plant of Asteraceae, were examined against A. flavus isolated from contaminated corn using agar dilution method to explore suitable natural preservative.

\section{Results and Discussion}

Using disk diffusion method, fungus growth diameter of A. flavus isolated from contaminated corn in the presence of aqueous extracts of some medicinal plants was successfully investigated in this study. The results of this study indicated that all the plants' extracts significantly inhibit A. flavus growth in comparison with each other and with the negative control (PEG) (Table 1). 
Table 1: Effects of aqueous extracts of the plants on A. flavus growth in PDA medium at different concentrations expressed as fungus growth diameters \pm SD and MIC (ppm) values.

\begin{tabular}{cccccccc}
\hline \multicolumn{7}{c}{ Fungus growth diameter $(\mathbf{m m})$} & \multirow{2}{*}{ MIC } \\
\hline Conc. $(\mathbf{p p m})$ & $\mathbf{1 0 0}$ & $\mathbf{2 0 0}$ & $\mathbf{3 0 0}$ & $\mathbf{4 0 0}$ & $\mathbf{5 0 0}$ & $\mathbf{6 0 0}$ & \\
\hline T. vulgaris & $24.6 \pm 4.7$ & $14.6 \pm 3.7$ & $12.3 \pm 0.5$ & $11.0 \pm 1.0$ & $1.1 \pm 0.7$ & $0 \pm 0$ & 600 \\
Z. multiflora & $29.6 \pm 0.5$ & $14.6 \pm 1.5$ & $13.0 \pm 1.7$ & $11.6 \pm 0.5$ & $6.3 \pm 1.1$ & $0 \pm 0$ & 600 \\
C. tinctorius & $31.3 \pm 1.5$ & $29.0 \pm 1.0$ & $25.6 \pm 1.5$ & $21.0 \pm 1.7$ & $17.3 \pm 2.5$ & $1.3 \pm 0.5$ & $>600$ \\
M. piperita & $31.3 \pm 1.1$ & $23.6 \pm 2.3$ & $17.0 \pm 2.4$ & $14.0 \pm 1.0$ & $11.0 \pm 1.0$ & $10.0 \pm 0$ & $>600$ \\
M. pulegium & $38.3 \pm 2.8$ & $27.6 \pm 3.0$ & $20.0 \pm 0$ & $18.6 \pm 1.1$ & $13.6 \pm 1.1$ & $10.0 \pm 0.5$ & $>600$ \\
C. senna & $34.6 \pm 1.5$ & $27.0 \pm 2.6$ & $25.0 \pm 0$ & $20.3 \pm 0.5$ & $18.6 \pm 1.5$ & $10.0 \pm 0$ & $>600$ \\
O. basilicum & $40.0 \pm 0$ & $26.6 \pm 2.8$ & $24.6 \pm 1.2$ & $20.6 \pm 1.1$ & $17.6 \pm 2.0$ & $11.6 \pm 2.8$ & $>600$ \\
\hline Control & $60.0 \pm 0$ & $59.3 \pm 0.5$ & $58.6 \pm 0.5$ & $58.3 \pm 0.5$ & $58.3 \pm 0.5$ & $57.6 \pm 0.5$ & - \\
\hline
\end{tabular}

Conc.: concentrations, MIC: minimum inhibitory concentration, ppm: part per million, control: polyethylene glycol.

Inhibition activity of all extracts was enhanced with an increase in their concentrations. Among them, the aqueous extracts of thyme (T. vulgaris) and zataria (Z. multiflora) with concentration of $600 \mathrm{ppm}$ completely arrested the fungus growth and effectively prohibited the fungus growth even at lower concentrations (200-500 ppm) in comparison with other extracts and the negative control. Inhibition effects of the extracts of thyme and zataria in concentration of $500 \mathrm{ppm}$ on the fungus growth were similar to safflower (C. tinctorius) in concentrations of $600 \mathrm{ppm}(p<0.05)$. The growth of $A$. flavus have been effectively inhibited by safflower extract at high concentration $(600 \mathrm{ppm})$ with fungus growth diameter of $1.3 \pm 0.5 \mathrm{~mm}$, but the extracts of peppermint, pennyroyal, senna and basil exhibited lower activity against the fungus in comparison to thyme, zataria and safflower extracts.

In addition, MIC values of both, thyme and zataria were assessed as $600 \mathrm{ppm}$, while for other plants it was defined more than 600 ppm. Previous study, as it summarized in Table 2, has mostly examined antifungal activity of plants oils, for example essential oils of T. vulgaris, Z. multiflora, M. piperita, M. pulegium and $O$. basilicum demonstrated inhibitory activity against growth of $A$. flavus and other microorganisms ${ }^{18,21-23,30}$. However, in this investigation, aqueous extracts of $T$. vulgaris and $Z$. multiflora mostly arrested growth of the fungus related to their polar chemical constituents, which are water soluble. The results of our study are in consistency with previous investigation, which suggested that aqueous extracts of thyme and coriander mostly inhibit the isolated strain of A. flavus followed by dill and rose extracts ${ }^{31}$. Result of an experiment showed that safflower, which was woundinoculated with Phytophthora drechsleri produces a polyacetylene compound that inhibits the growth of the mentioned fungus in vitro ${ }^{32}$. Both polar and non-polar extracts of $C$. senna did not exhibit antifungal activity toward A. niger ${ }^{26}$. While, antimicrobial activity of some Senna spp. against different microorganisms in the previous studies was demonstrated. For instance, aqueous extract of $S$. obtusifolia containing alkaloids and flavonoids prevented A. niger more than other extract of the plant ${ }^{33}$. Moreover, an unidentified flavonoid glycoside isolated from leaves of $S$. alata prohibited growth of $A$. niger with MIC value of $70 \mu \mathrm{g} / \mathrm{mL}^{34}$. Hairy root culture of $O$. basilicum produced rosmarinic acid that induced cytoskeleton damages with broken interseptas and convoluted cell surfaces in A. niger ${ }^{35}$. Based on the aforementioned studies, the antifungal activity of the plants attributed to the various kinds of secondary metabolites like flavonoids, alkaloids, phenolic acids and the essential oils ${ }^{34,35}$. 
Table 2: Antifungal activity of different plant samples against Aspergillus spp. reported in previous studies.

\begin{tabular}{|c|c|c|c|}
\hline Plant sample & Extract & Microorganism & References \\
\hline $\begin{array}{l}\text { T. vulgaris, Satureja hortensis, Syzygium } \\
\text { aromaticum }\end{array}$ & essential oil & A. flavus & [9] \\
\hline Polymnia sonchifolia & aqueous extract & A. flavus & {$[10]$} \\
\hline T. vulgaris & essential oil & A. parasiticus, A. flavus & {$[11,14]$} \\
\hline $\begin{array}{c}\text { T. vulgaris, } T \text {. tosevii, } M . \text { spicata, } M . \\
\text { piperita }\end{array}$ & essential oil & $\begin{array}{c}\text { A. niger, A. ochraceus, } \\
\text { A. versicolor, } \\
\text { A. flavus, A. terreus }\end{array}$ & {$[12]$} \\
\hline $\begin{array}{c}\text { Cinnamomum zeylanicum, M. piperita, } O . \\
\text { basilicum, Origanum vulgare, Teloxys } \\
\text { ambrosioides, Syzygium aromaticum, } T . \\
\text { vulgaris }\end{array}$ & essential oil & A. flavus & [13] \\
\hline Z. multiflora & essential oil & A. parasiticus, A. flavus & {$[17,18]$} \\
\hline T. vulgaris & essential oil & Aspergillus spp. & {$[15]$} \\
\hline M. piperita & essential oil & $\begin{array}{l}\text { A. fumigatus, A. flavus, } \\
\text { A. ochraceus }\end{array}$ & {$[22]$} \\
\hline M. pulegium & essential oil & A. niger, A. flavus & {$[24,25]$} \\
\hline $\begin{array}{l}\text { T. vulgaris, Coriandrum sativum, Anethum } \\
\text { graveoles, Rosa damascena }\end{array}$ & aqueous extract & A. flavus & [26] \\
\hline S. obtusifolia & aqueous extract & A. niger & [28] \\
\hline
\end{tabular}

Antifungal activity of the tested plants in the present study also can be attributed to the various polar phytochemicals in their aqueous extracts.

\section{Conclusion}

Taking together, in our study the plants belong to Lamiaceae family, except for O. basilicum, along with safflower (Asteraceae) were more active against the fungus than species of senna (Fabaceae). Based on the results of this study, it can be proposed that aqueous extract of thyme, zataria and safflower effectively inhibit A. flavus growth attributed to their polar secondary metabolites and are suitable as natural antifungal agents to prevent the fungus activity. Hence, these three extracts inhibited fungus growth most effectively with concentration of $600 \mathrm{ppm}$ in comparison with other tested extracts. While, fungus growth ranged between 10.0-11.6 mm in the presence of other extracts with concentration of 600 ppm. Evaluation of synergistic activity of the examined plants in prevention of the fungus growth for longer periods of time followed by organoleptic properties such as taste and smell of the processed food with those active extracts followed by isolation and identification of their active compounds are recommended for the further studies.

\section{Acknowledgements}

This study was supported by Tehran University of Medical Sciences (grant No: 93/02/56/25250). 


\section{Experimental Section}

\section{General}

All chemicals used in this study were in analytical grades. Potato dextrose agar (PDA) medium was purchased from Merck Company (Darmstadt, Germany) and Millipore membrane filter $(0.22 \mu \mathrm{m})$ from Membrane Solution (Ohio, USA).

\section{Plant materials}

Aerial parts of the plants including aerial parts of Z. multiflora, T. vulgaris, M. pulegium, $M$. piperita, $C$. senna, and $O$. basilicum along with flowers of safflower $C$. tinctorius were collected from Abarkuh city, Yazd province, Iran in spring of 2012. The samples of the plants were cleaned and dried at room temperature in the shade. Powdered plant materials $(100 \mathrm{~g})$ were extracted with distilled water (DW) three times by percolator apparatus each time $48 \mathrm{~h}$. All the extracts were dried in the air flow. Extracts were consequently dissolved in DW to get different concentrations including 100, 200, 300, 400, 500 and 600 ppm.

\section{Antifungal assay}

The antifungal effects of the plants extracts were tested using agar dilution method. The fungus species was obtained from contaminated corn keeping in the storehouse of companies providing livestock food. Contaminated samples were stored in plastic bags, conveyed to the laboratory and stored in refrigerator at $4{ }^{\circ} \mathrm{C}$ until analyzing. Samples were disinfected using hypochlorite sodium (2\%) performed under laminar flow and consequently washed with DW for 30 seconds. Afterwards, the contaminated parts of the corns were transferred to PDA medium and stored at $25^{\circ} \mathrm{C}$ for 3 days. Colonies of the fungus with microscopic features of grown A. flavus were transferred to new PDA mediums. The plants extracts were filtered using Millipore membrane filter $(0.22 \mu \mathrm{m})$ and mixed with culture medium to obtain concerned concentrations (100-600 ppm). The blank disks $(6 \mathrm{~mm})$ were subsequently impregnated in the fungus suspension $\left(1 \times 10^{6} \mathrm{CFU} / \mathrm{mL}\right)$ and placed in the center of mediums. In order to eliminating osmotic effects of the extracts on the fungus growth, PEG with equal osmotic potential of the plants extracts were added to PDA medium as a negative control. All mediums were kept at $25^{\circ} \mathrm{C}$ and growth diameters of the fungi were measured at the end of 7 days. The tests were performed at least in triplicate and the mean diameters of the fungus growth were calculated as well. Minimum inhibitory concentration (MIC) values were also assessed as the lowest concentration of the plants extracts, which inhibited the fungus growth.

\section{Statistical analysis}

Growth diameters of the fungi at different concentrations of all the extracts and PEG were compared using SPSS software. All data were expressed as mean \pm standard deviation (SD) and statistical significances were assessed by analyzing of variance (ANOVA) along with Duncan post hoc test for multiple comparisons and $p<0.05$ implies significance.

\section{References}

1- E.K. Cassel, B. Campbell, M. Draper and B. Epperson, Cooperative Extension Service / College of Agriculture \& Biological Sciences / USDA, 2001. 
2- N. Taheri, S. Semnani, G. Roshandel, M. Namjoo, H. Keshavarzian, A.G. Chogan, F. Ghasemi Kebria and H. Joshaghani, Iranian journal of public health, 2012, 41, 9, 42-47.

3- S. S. Hua, C. E. McAlpin, P. K. Chang and S. B. L. Sarreal, Mycotoxin Research, 2012, 28, 1, 67-75.

4- E. L. De Souza, E. O. Lima, K. R. L. Freire and C. P. De Sousa, Brazilian Archives of Biology and Technology, 2005, 48, 245-250.

5- A. A. Ismaiel, G. H. Rabie, S. E. Kenawey and M. Abd El-Aal, Brazilian Journal of Microbiology, 2012, 43, 4, 1355-1364.

6- D. L. Eaton and J. D. Groopman, The toxicology of aflatoxins: human health, veterinary and agricultural significance, San Diego, CA, Academic Press, 1994.

7- S. Amaikel and N. P. Keller, Annual Review of Phytopathology, 2011, 49, 107-133.

8- O. Atanda, A. Oguntubo, O. Adejumo, J. Ikeorah and I. Akpan, Chemosphere, 2007, 68, 8, 1455-1458.

9- M. Omidbeygi, M. Barzegar, Z. Hamidi and H. Naghdibadi, Food Control, 2007, 18, 12, 1518-1523.

10- M. M. Pinto, E. Gonçalez, M. H. Rossi, J. D. Felício, C. S. Medina, M. J. B. Fernandes and I. C. Simoni, Brazilian Journal of Microbiology, 2001, 32, 127-129.

11- I. Rasooli and M. R. Abyaneh, Food Control, 2004, 15, 6, 479-483.

12- M. D. Sokovic, J. Vukojevic , P. D. Marin, D. D. Brkic, V. Vajs and L. J. van Griensven, Molecules, 2009, 14, 1, 238-249.

13- H. Sajed, A. Sahebkar and M. Iranshahi, Journal of Ethnopharmacology, 2013, 145, 686-698.

14- E. A. Eman and L. E. Craker, Journal of Herbs, Spices \& Medicinal Plants, 2010, 15, 361-367

15- S. J. Lee, K. Umanob, T. Shibamotoc, K. G. Lee, Food Chemistry, 2005, 91, 131-137.

16- S. Khan, J. M. Khanda, F. Al-Qurainy, Z. A. Malik, Saudi Journal of Biological Sciences, 2011, 18, 287-2 92.

17- N. Nimbkar, Times Agricultural Journal, 2002, 2, 32-36.

18- R. Montes-Belmont and M. Carvajal, Journal of Food Protection, 1998, 5, 513-648.

19- A. Kumar, R. Shukla, P. Singh, C. S. Prasad and N. K. Dubey, Innovative Food Science and Emerging Technologies, 2008, 9, 575-580.

20- M. Segvic Klaric, I. Kosalec, J. Mastelic, E. Pieckova and S. Pepeljnak, Letters in Applied Microbiology, 2007, 44, 36-42.

21- K. Zomorodian, M. J. Saharkhiz, M. J. Rahimi, A. Bandegi, G. Shekarkhar, A. Bandegani, K. Pakshir and A. Bazargani, Pharmacognosy Magazine, 2011, 7, 25, 53-59.

22- H. Gandomian, A. Misaghi, A. Akhondzadeh Basti, S. Bokaei, A. Khosravi, A. Abbasifar and A. J. Javan, Food and Chemical Toxicology, 2009, 47, 2397-2400.

23- I. Rasooli, M. H. Fakoor, A. Allameh, A. B. Rezaee and P. Owlia, Journal of Medicinal Plants, 2009, 8, 5, 97-104.

24- A. Lo'pez-Malo, S. M. Alzamora and E. Palou, International Journal of Food Microbiology, 2005, 99, 119-128.

25- D. J. Daferera, B. N. Ziogas and M. G. Polissiou, Journal of Agricultural and Food Chemistry, 2000, 48, 2576-2581.

26- H. Kamal, M. Hassan, M. N. Parvin, M. Hasan, S. Islam and A. Haque, Journal of applied pharmaceutical science, 2012, 2, 6, 186-190. 
27- M. Skrinjar, A. Mandi, A. Misan, M. Saka, L. Sari and M. Zec, Zbornik Matice Srpske za Prirodne Nauke, 2009, 116, 131-139.

28- M. Moghtader, African Journal of Plant Science, 2013, 7, 11, 521-527.

29- H. Hajlaoui, N. Trabelsi, E. Noumi, M. Snoussi, H. Fallah, R. Ksouri and A. Bakhrouf, World Journal of Microbiology \& Biotechnology, 2009, 25, 2227-2238.

30- M. Mahboubi and G. Haghi, Journal of Ethnopharmacology, 2008, 119, 325-327.

31- S. Yahya Abadi, E. ZibaNejad and M. Doodi, Iranian Journal of Herbal Drugs, 2011, 2, 1, 69-81.

32- E. H. Allen and C. A. Thomas, Phytochemistry, 1971, 10, 7, 1579-1582.

33- J. H. Doughari, A. M. El-mahmood and I. Tyoyina, African Journal of Pharmacy and Pharmacology, 2008, 2, 1, 007-013.

34- J. A. Owoyale, G. A. Olantunji and S. O. Oguntoye, Journal of Applied Sciences and Environmental Management, 2005, 9, 3, 105-107.

35- H. P. Bais, T. S. Walker, H. P. Schweizer and J. M. Vivanco, Plant Physiology and Biochemistry, 2002, 40, 983-995. 